\title{
Postural changes of the vertebral-pelvic balance in patients with Hip-Spine syndrom
}

\author{
A.O. Kotelnikov, S.O. Ryabykh, A.V. Burtsev
}

Ilizarov National Medical Research Centre for Traumatology and Orthopedics, Kurgan, Russian Federation

\begin{abstract}
Relevance It is known that the state of sagittal balance is strictly correlated with the quality of life of the patient. At the same time, reference values for correction of sagittal parameters of the spine are derived only from vertical radiographs. Current evidence shows that the use of only standardized sagittal parameters in the standing position for planning the volume of surgical reconstruction is erroneous. However, rare publications show the difference between the sagittal profile of the spine in the sitting and standing position related to age. There is no information on the profile in extended degenerative pathology of the spine. Aim of the study Comparative assessment of the variability of the parameters of the sagittal profile of patients with Hip-Spine syndrome in the standing and sitting positions and comparison with healthy subjects from the average population. Design A prospective case-control monocenter observational study with historical control. The study included 74 patients with "Hip-spine" syndrome at the age of $63 \pm 9.9$ (43 to 83) years at the time of examination. The recruitment period was 23 months. The main group was formed by 74 patients with Hip-Spine syndrome. The control group (58 subjects) was represented by healthy individuals from open sources on the average population. The criteria of the analysis were sagittal vertebral-pelvic parameters of the trunk - CL, TK, TLK, LL, PI, PT, SS, SVA. The calculation of sagittal parameters was performed with Surgimap Spine software. Results In all patients during the transition from standing to sitting, there was kyphotization of the thoracolumbar transition (mean TLK angle was $10.3^{\circ}-$ $145 \%$ ), a decrease in lumbar lordosis (mean LL angle - $23^{\circ}-44.4 \%$ ) with pelvic retroversion (PT: $18.6^{\circ}-126.5 \%$, SS: $18.3^{\circ}-51.6 \%$ ) and an increase in forward SVA deviation (10.5 mm - $25.5 \%)$. No significant changes in cervical lordosis and thoracic kyphosis were revealed. When comparing the average values of sagittal parameters of patients of the main and control groups, there were no significant differences. However, among all patients of the main group, there were 6 patients $(8.1 \%)$ in whom the difference in the parameters LL, SS, PT in the standing and sitting positions was less than $10^{\circ}$, which indicates a pronounced rigidity of the lumbosacral spine. Conclusion Postural sagittal vertebral-pelvic parameters of the trunk in the standing and sitting positions in patients with Hip-Spine syndrome differ significantly from each other. A key role in the changes is played by the position of the pelvis, which retains mobility, despite different severity of degenerative changes in the complex "hip joints-lumbosacral spine".
\end{abstract}

Keywords: hip-spine syndrome, sagittal balance of the trunk, postural parameters of sagittal balance, sagittal vertebral-pelvic parameters

\section{INTRODUCTION}

A man strives for harmony both in static and in dynamic actions to save energy throughout the day. In relation to the balance of the trunk in general and the spine in particular, it is determined by the concept of the J. Dubousset's cone of economy [14]. Assessment of the patient's sagittal profile plays an important role in planning surgical treatment of spinal pathology [5-12]. Sagittal balance and sagittal alignment are two different concepts in vertebrology. Sagittal alignment determines the combination of static parameters while the sagittal balance is dynamic parameters. Current spinal surgery focuses directly on sagittal alignment, and transpedicular fixation with interbody fusion serves as a guarantee of stability of the restored sagittal profile [13-19]. The most mobile and important role in the compensatory mechanisms of body imbalance is the complex "pelvis - lumbosacral spine" [20-23]. Recent studies have shown significant changes in lumbar lordosis and dynamic parameters of the pelvis in standing and sitting positions, but we have not found works on the study of spinal balance in patients with combined degenerative pathology in the complex "pelvis -lumbosacral spine". This circumstance substantiates the main research question and its purpose: Is there variability in the parameters of the patient's sagittal profile in the standing and sitting positions? And second, how they correlate with the normal values found in the community population. The nosological group "hip-spine syndrome" was chosen by us as a common condition with an alleged a priori impaired sagittal profile.

Purpose A comparative assessment of the variability of the parameters of the sagittal profile of patients with hip-spine syndrome in the standing and sitting positions in relation to the normal values of the average population.

Study design a continuous prospective monocenter case-control study with historical control.

Level of Evidence 3a (according to UK Oxford, version 2009).

Selection of patients for the main group followed inclusion criteria:

- cohort principle of location (patients of the Ilizarov Centre) and time (recruitment period from January 2016 to December 2018), surgical team (planning of the surgical protocol);

- nosological principle of the unity of clinical manifestations (patients with degenerative pathology confirmed by radiological findings in the complex "hip joints - lumbosacral spine" (HJ-LSS complex) 
associated with pain in both the hip joint (s) and in the lumbosacral spine).

The following criteria were defined as exclusion criteria:

- patients with unstable somatic status, neurological disorders (including severe pain syndrome) and severe contractures of large lower limb joints, restricting upright and sitting positions;

- patients with dysplasia and abnormalities of the spine, combined with deformity or pain, with injuries of the spine, pelvis, and hip joints; with any inflammatory and oncological diseases in the spine and hip joints.

Patients' recruitment period: January 2016 through December 2018 (total, 36 months).

Based on the selected criteria, the main group included the results of 74 patients. The gender ratio was $q-26$ (35.1\%), $0-48$ (64.9\%). The average age of the subjects was $63 \pm 9.9$ years and ranged from 43 to 83 years. Patients of the control group (healthy subjects) had available values of the difference in sagittal spinal-pelvic parameters in standing and sitting positions.

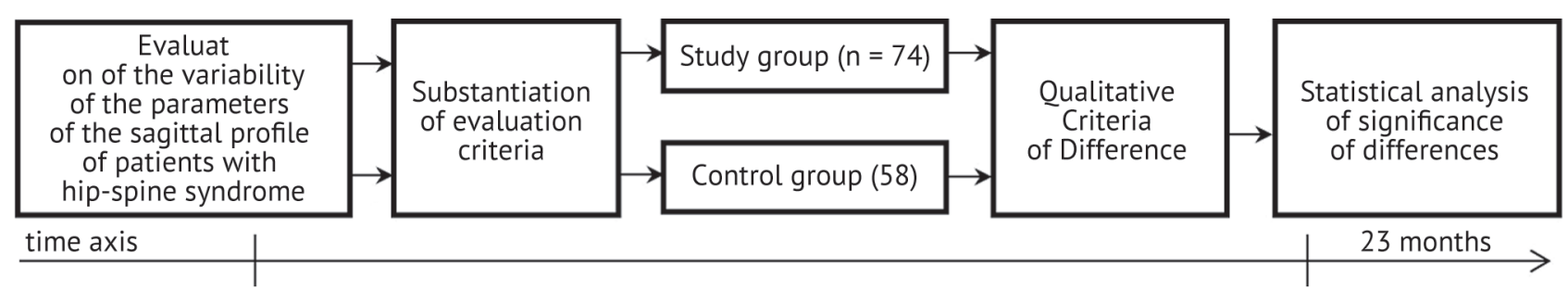

Fig. 1 Diagram of study design

\section{MATERIAL AND METHODS}

All patients in the study group underwent radiological and clinical examination.

Radiological study included lateral X-ray telemetry of the spine and pelvis in the standing position and sitting on a chair. Standing and sitting positions were standardized as the most correct in accordance with the studies of several authors Sieh K.M. (2018), Cho I.Y. (2015): the standing position required to stand as straight as possible, not bending forward or backward, hands on the clavicles; the sitting position required bending of the hips and knees at an angle of 90 , and also to sit as straight as possible, not bending forward or backward, hands on the clavicles.

Clinical study included detection of the hipspine syndrome type according to Offierski, MacNab [40]; assessment of the functional status of patients according to ODI, Harris, as well as assessment of the severity of pain according to VAS LBP (low back pain) and VAS LEP (low extremity pain),

Criteria for evaluation According to X-ray telemetry of the spine and pelvis, eight sagittal parameters of the spinal-pelvic relationships - CL, TK, TLK, LL, PI, PT, SS, SVA - were evaluated. The Surgimap software was used for calculation and integral estimation of the parameters. The criteria for sagittal parameters of the trunk and spinal-pelvic relationships in the sitting and standing positions were identified by D. Hey (2016), being the most valid and reliably correlated with the quality of life.

Statistical data analysis was performed using the Statistical Package for the Social Sciences (SPSS) software, version 22.0 (SPSS Inc., Chicago, IL, USA). Normality of distribution of the studied parameters was checked using the method of descriptive statistics. For the intergroup comparative assessment of differences in the average values of the analyzed parameters, the non-parametric H-Kruskal-Wallace criterion and the correlation analysis with the r-Pearson criterion were used due to a small number of samples. Statistical differences were considered significant at bilateral $\mathrm{p} \leqslant 0.05$.

\section{RESULTS}

There were 57 patients with simple hip-spine syndrome $(76.9 \%), 17$ with complex syndrome $(22.1 \%)$. In the group with simple syndrome, a subgroup with a predominance of the hip joint pathology was distinguished $(\mathrm{n}=43,58.0 \%)$ and a subgroup with a predominance of the lumbosacral spine symptoms $(n=14,18.9 \%)$. Different combinations in neurological status were detected, vertebrogenic pain $(\mathrm{n}=74,10 \%)$ and VAS $=5.7 \pm 2.5$, arthrogenic pain $(n=74,100 \%)$ with $\mathrm{VAS}=4.6 \pm 2.1$, neurogenic intermittent claudication $(\mathrm{n}=10,13.5 \%)$, radiculopathy $(\mathrm{n}=10$, $13.5 \%$ ). The Harris Hip Score of $65.8 \pm 13.6$ and ODI of $42.3 \pm 13.5$ indicated a significant deterioration in the patients' quality of life. According to the Harris questionnaire, most patients $(51,68.9 \%)$ responded to the question about the ability to sit on a chair with "b" or "c" answers (a - comfortable in an ordinary chair for one hour, $b$ - in high chair for half an hour, $\mathrm{c}$ - cannot sit on any chair). 
According to X-ray examination, all patients had varying severity of coxarthrosis (grade 1,2 patients (2.7\%); grade 2 stages, 16 patients (21.6\%); grade 3, $56(75.7 \%)$. Clinical examination revealed combined contractures of the hip joints with an extension deficiency of up to $10^{\circ}$ in 58 patients (78.4\%). Degenerative changes in the lumbar spine were observed in all patients of the study group $(n=74) .52(92.85 \%)$ patients had osteophytes of the vertebral bodies, a decrease in the height of the intervertebral discs and foramen was detected in $43(76.78 \%)$ patients, arthrosis of the facet joints in $48(85.71 \%)$. In all cases, the changes were localized in the lower lumbar segments (L4-S1).

The transition from a standing position to a sitting position caused kyphotization of the thoracolumbar junction in all patients in comparison with the standing position (average value of the change in TLK angle was $10.3^{\circ}, 145 \%$ ), decrease in lumbar lordosis (average value of change in the LL angle of $23.0^{\circ}, 44.4 \%$ ) with pelvic retroversion $\left(\mathrm{PT}=18.6^{\circ}, 126.5 \%, \mathrm{SS}=18.3^{\circ}\right.$, $51.6 \%$ ) and an increase in positive SVA deviation (10.5 mm, $25.5 \%$ ) due to leaning forward. Significant changes in cervical lordosis and thoracic kyphosis were not detected. Statistical analysis to assess the significance of differences (Table 1), according to the $\mathrm{H}$ - Kruskal-Wallace criterion indicates the significance of differences in LL, PT, SS in the sitting and standing positions, $\mathrm{p} \leqslant 0.05$. According to the correlation analysis using the r-Pearson criterion (SPSS, version 22.0), a strong relationship was noted only between the LL and SS parameters $(r=0.84)$.

When comparing the average values of the angles of change of the spinal-pelvic parameters in patients of the main group with the data of the comparison group (healthy individuals) according to H. Hey (2016) [39], no significant differences were noted with the exception of TK, which changed more significantly in healthy individuals (Table . 2). However, among all patients of the study group, it is necessary to mentions six patients (8.1\%), in whom the difference in LL, SS, PT parameters in the standing and sitting position was less than $10^{\circ}$, which indicates a pronounced rigidity of the lumbosacral spine (five of them belonged to the group with complex hip-spine syndrome and one to the group with a simple syndrome, a subgroup with a predominance of symptoms of lesions of the lumbosacral spine). The difference in sagittal balance in the sitting and standing positions is presented in Figure 2.

Table 1

Statistical processing of the spinal-pelvic parameters in the sagittal plane

\begin{tabular}{|c|c|c|c|}
\hline Parameter & Standing & Sitting & Significance of difference \\
\hline \multicolumn{4}{|c|}{ TLK (thoracolumbar transition) } \\
\hline Minimum & -26 & -2 & \multirow{3}{*}{$\mathrm{p}=0.06$} \\
\hline Maximum & 40 & 48 & \\
\hline Mean & $7.1 \pm 11.8$ & $17.4 \pm 10.7$ & \\
\hline \multicolumn{4}{|l|}{ LL (lumbar lordosis) } \\
\hline Minimum & -29 & -4 & \multirow{3}{*}{$\mathrm{p}=0.04$} \\
\hline Maximum & -91 & -79 & \\
\hline Mean & $-54.1 \pm 13.2$ & $-30.9 \pm 17.1$ & \\
\hline \multicolumn{4}{|l|}{ PT (pelvic tilt) } \\
\hline Minimum & -5 & 7 & \multirow{3}{*}{$\mathrm{p}=0.05$} \\
\hline Maximum & 29 & 56 & \\
\hline Mean & $13.9 \pm 7.3$ & $34.2 \pm 11.8$ & \\
\hline \multicolumn{4}{|l|}{ SS (sacrum slope) } \\
\hline Minimum & 18 & -6 & \multirow{3}{*}{$\mathrm{p}=0.04$} \\
\hline Maximum & 53 & 47 & \\
\hline Mean & $38.6 \pm 9.0$ & $18.7 \pm 12.4$ & \\
\hline \multicolumn{4}{|c|}{ SVA (sagittal vertical axis) } \\
\hline Minimum & -25 & -11 & \multirow{3}{*}{$\mathrm{p}>0.09$} \\
\hline Maximum & 145 & 132 & \\
\hline Mean & $41.1 \pm 40.7$ & $51.6 \pm 29.1$ & \\
\hline \multicolumn{4}{|c|}{ TK (thoracic kyphosis) } \\
\hline Minimum & 1 & 7 & \multirow{3}{*}{$\mathrm{p}=0.08$} \\
\hline Maximum & 65 & 60 & \\
\hline Mean & $31.9 \pm 12.9$ & $33.7 \pm 11.9$ & \\
\hline \multicolumn{4}{|l|}{ CL (cervical lordosis) } \\
\hline Minimum & 11 & 4 & \multirow{3}{*}{$\mathrm{p}>0.09$} \\
\hline Maximum & -62 & -81 & \\
\hline Mean & $-23.1 \pm 17.7$ & $-25.7 \pm 18.6$ & \\
\hline
\end{tabular}


Table 2

Comparison of mean values of the angle of change of the spinal-pelvic parameters (between sitting and standing positions) among healthy individuals and patients with hip-spine syndrome

\begin{tabular}{|l|c|c|}
\hline \multirow{2}{*}{\multicolumn{1}{|c|}{ Parameters }} & Healthy subjects & Hip-spine patients \\
\cline { 2 - 3 } & \multicolumn{2}{|c|}{ Mean angle of change } \\
\hline LL (lumbar lordosis) & $24.6 \pm 12.7$ & $23.0 \pm 16.2$ \\
\hline SS (sacral slope) & $18.8 \pm 8.7$ & $18.3 \pm 9.4$ \\
\hline PT (pelvic tilt) & $19.5 \pm 7.9$ & $18.6 \pm 8.8$ \\
\hline TK (thorathic kyphosis) & $8.6 \pm 7.2$ & $2.2 \pm 6.3$ \\
\hline
\end{tabular}

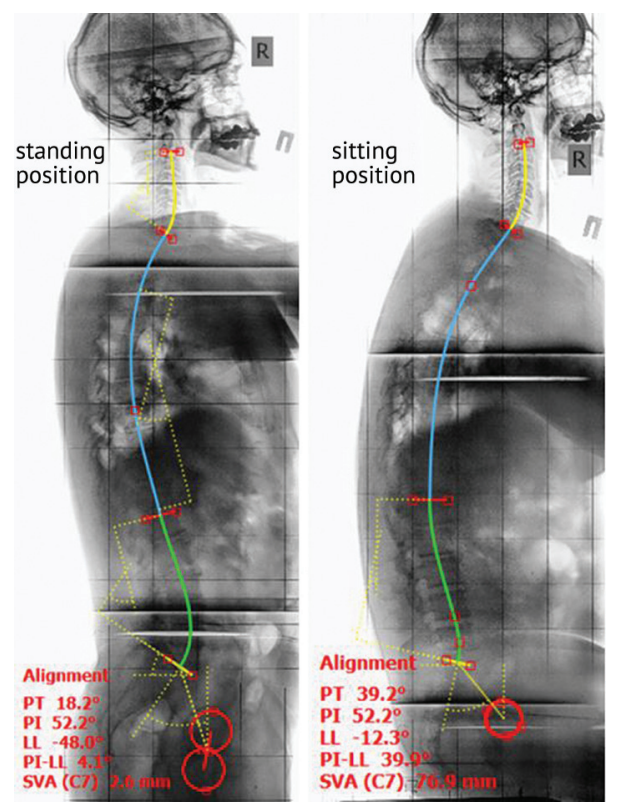

Fig. 2 X-ray telemetry of the spine in the lateral projection in the sitting and standing positions of a 62-year-old patient with a simple type of hip-spine syndrome (subgroup with a predominance of hip joint pathology). The difference between the position of the pelvis and the value of lumbar lordosis between the standing and sitting positions was: PT: $24^{\circ}-131 \%$, LL: $-35.7^{\circ}-74 \%$

\section{DISCUSSION}

Currently, the "gold" standard in spinal surgery is to restore the natural curvature of the spine characteristic for standing position. This is based on the assumption that standing is the most preferable posture for the spine [24-27]. Nevertheless, this statement is debatable, since for a significant number of people a more functional posture may be sitting, especially for elderly patients with severe degenerative changes in the spine and joints (a group of people with hip-spine syndrome).

A number of foreign authors who evaluated the functional activity of healthy children and adults, indicate that a modern person spends most of his day time sitting rather than standing, which may be due to an increase in the technogenicity of the life process and robotization, in which the physical work of a person is a secondary activity [28-31]. Therefore, a hypothesis was formed that surgical intervention on the lumbosacral spine with its stabilization in patients who need it and who spend most of their time in a sitting position should involve fixation of the spine in the sagittal alignment corresponding to the sitting position.

The sagittal alignment of the trunk differs significantly in the standing and sitting positions. In sitting, the pelvis rotates backward and hypolordization of the lumbar spine is observed [28, 32-34]. Our study confirms the conclusion of these studies and points to comparable mobility of the lumbosacral spine in healthy people and people with significant degenerative changes in LSS and hip joints. Six patients (8.1\%) had the difference in LL, SS, PT parameters less than $10^{\circ}$ in the standing and sitting positions that showed absent compensatory capabilities due to the pronounced clinical and radiological manifestations of hip-spine syndrome.

Moreover, in most cases, despite the retained mobility of LSS and HJs, the sitting position may cause discomfort and pain. In our study, it was found in 51 patients $(68.9 \%)$ and was, in our opinion, associated with pronounced changes in the complex under the investigation. All this suggests that the lumbosacral spine plays an important role as a compensator and regulator of the body balance. However, the assumption that it is necessary for such patients to maintain the sagittal alignment of the sitting position is, in our opinion, incorrect and unacceptable due to the fact that hypolordosis of the lumbar region (especially when the lower lumbar segments are fused) will bring the patient out of the J. Dubousset's "cone of economy" and will result in deviation of the gravity line forward in the state of 
being in the vertical position due to pelvic anteversion and absence of compensatory capabilities of the lumbar spine (due to the lack of mobility).

This statement is confirmed by the results of our study and the publications of several authors who showed high correlation between the SS parameter and lumbar lordosis, as well as the fact of the pelvis changes in the sitting and standing positions [35-38]. Thus, there is every reason to believe that multisegmented stabilization of the lumbar spine in the position corresponding to the "sitting" alignment, while maintaining the mobility of the pelvis, will make verticalization of the patient difficult and thus will worsen patient's self-care and ability of daily activities. Correction and stabilization of the lumbar spine within the "cone of economy" allows patients to acquire the sitting position, since the load on the muscles to maintain a sitting posture can be leveled by changing the position of the back of the chair to support the spine.

\section{CONCLUSIONS}

There are significant differences in postural sagittal spinopelvic trunk parameters in the standing and sitting positions in patients with hip-spine syndrome.

A key role in the changes is played by the position of the pelvis.

In most cases, the pelvis retains the mobility and the function of the body balance regulator, despite pronounced clinical and radiological manifestations of the hip-spine syndrome.

Limitations The monocentral character with a limited cohort in number, no doubt, lowers the level of evidence of the patterns obtained, which not only excludes the categorical nature of the conclusions but also determines the goal for a multicenter research on the topic under this study.

\section{REFERENCES}

1. Hasegawa K., Okamoto M., Hatsushikano S., Shimoda H., Ono M., Watanabe K. Normative values of spinopelvic sagittal alignment, balance, age, and health-related quality of life in a cohort of healthy adult subjects. Eur. Spine J., 2016, vol. 25, no. 11, pp. 36753686. DOI: 10.1007/s00586-016-4702-2.

2. Berthonnaud E., Dimnet J., Roussouly P., Labelle H. Analysis of the sagittal balance of the spine and pelvis using shape and orientation parameters. J. Spinal Disord. Tech., 2005, vol. 18, no. 1, pp. 40-47. DOI: 10.1097/01.bsd.0000117542.88865.77.

3. Dubousset J. Three-dimensional analysis of the scoliotic deformity. In: Weinstein S.L., ed. The pediatric spine: principles and practice. New York, Raven Press. Ltd., 1994, pp. 479-496.

4. Ames C.P., Smith J.S., Scheer J.K., Bess S., Bederman S.S., Deviren V., Lafage V., Schwab F., Shaffrey C.I. Impact of spinopelvic alignment on decision making in deformity surgery in adults: A review. J. Neurosurg. Spine, 2012, vol. 16, no. 6, pp. 547-564. DOI: $10.3171 / 2012.2$.SPINE11320.

5. Schwab F., Dubey A., Gamez L., El Fegoun A.B., Hwang K., Pagala M., Farcy J.P. Adult scoliosis: prevalence, SF-36, and nutritional parameters in an elderly volunteer population. Spine, 2005, vol. 30, no. 9, pp. 1082-1085. DOI: 10.1097/01.brs.0000160842.43482.cd.

6. Schwab F., Patel A., Ungar B., Farcy J.P., Lafage V. Adult spinal deformity-postoperative standing imbalance: how much can you tolerate? An overview of key parameters in assessing alignment and planning corrective surgery. Spine, 2010, vol. 35, no. 25, pp. 2224-2231. DOI: 10.1097/BRS.0b013e3181ee6bd4.

7. Lu D.C., Chou D. Flatback syndrome. Neurosurg. Clin. N. Am., 2007, vol. 18, no. 2, pp. 289-294. DOI:10.1016/j.nec.2007.01.007.

8. Lafage V., Schwab F., Patel A., Hawkinson N., Farcy J.P. Pelvic tilt and truncal inclination: two key radiographic parameters in the setting of adults with spinal deformity. Spine, 2009, vol. 34, no. 17, pp. E599-E606. DOI:10.1097/BRS.0b013e3181aad219.

9. Schwab F., Lafage V., Patel A., Farcy J.P. Sagittal plane considerations and the pelvis in the adult patient. Spine, 2009, vol. 34, no. 17, pp. 1828-1833. DOI:10.1097/BRS.0b013e3181a13c08.

10.Schwab F.J., Patel A., Shaffrey C.I., Smith J.S., Farcy J.P., Boachie-Adjei O., Hostin R.A., Hart R.A., Akbarnia B.A., Burton D.C., Bess S., Lafage V. Sagittal realignment failures following pedicle subtraction osteotomy surgery: are we doing enough?: Clinical article. J. Neurosurg. Spine, 2012, vol. 16, no. 6, pp. 539-546. DOI:10.3171/2012.2.SPINE11120.

11.Klineberg E., Schwab F., Smith J.S., Gupta M.C., Lafage V., Bess S. Sagittal spinal pelvic alignment. Neurosurg. Clin. N. Am., 2013, vol. 24, no. 2, pp. 157-162. DOI:10.1016/j.nec.2012.12.003.

12.Glassman S.D., Bridwell K., Dimar J.R., Horton W., Berven S., Schwab F. The impact of positive sagittal balance in adult spinal deformity. Spine, 2005, vol. 30, no. 18, pp. 2024-2029. DOI: 10.1097/01.brs.0000179086.30449.96.

13.Kalinin A.A., Okoneshnikova A.K., Byvaltsev V.A. Lechenie patsientov s degenerativnymi zabolevaniiami poiasnichnokresttsovogo otdela pozvonochnika s ispolzovaniem novoi metodiki fasetochnoi stabilizatsii implantatom Facet Wedge [Treatment of patients with degenerative diseases of the lumbosacral spine using Facet Wedge new technique of facet stabilization with an implant]. Sovremennye Tekhnologii v Meditsine, 2017, vol. 9, no. 2, pp. 131-140. (in Russian)

14.Dubousset J. Dostizhenie garmonii v 3d-korrektsii deformatsii pozvonochnika [Achieving harmony in 3D-correction of the spine deformities]. Khirurgiia Pozvonochnika, 2018, vol. 15, no. 1, pp. 101-109. (in Russian)

15.Horton W.C., Brown C.W., Bridwell K.H., Glassman S.D., Suk S.I., Cha C.W. Is there an optimal patient stance for obtaining a lateral 36" radiograph? A critical comparison of three techniques. Spine, 2005, vol. 30, no. 4, pp. 427-433. DOI: 10.1097/01. brs.0000153698.94091.f8.

16.Legaye J., Duval-Beaupère G. Sagittal plane alignment of the spine and gravity: a radiological and clinical evaluation. Acta Orthop. Belg., 2005, vol. 71, no. 2, pp. 213-220.

17.Dubousset J., Challier V., Farcy J.P., Schwab F.J., Lafage V. Spinal alignment versus spinal balance In: R.W. Haid, F.J. Schwab, C.I. Shaffrey, J.A. Youssef, eds. Global Spinal Alignment: Principles, Pathologies, and Procedures. St. Louis, MO, Quality Medical Publishing, 2015, pp. 3-9.

18.Legaye J. Analysis of the dynamic sagittal balance of the lumbo-pelvic-femoral complex. In: Klika V., ed. Biomechanics in Applications. Croatia, InTech., 2011, pp. 221-246. Available at: http://www.intechopen.com/books/biomechanics-in-applications/ analysis-of-the-dynamic-sagittal-balanceofthe-lumbo-pelvic-femoral-complex (accessed 08.05.2019).

19.Belykh E., Kalinin A.A., Martirosyan N.L., Kerimbayev T.T., Theodore N., Preul M.C., Byvaltsev V.A. Facet joint fixation and Anterior, Direct Lateral, and Transforaminal Lumbar Interbody Fusions for treatment of degenerative lumbar disc diseases: retrospective cohort study of a new minimally invasive technique. World Neurosurg., 2018, vol. 114, pp.1e959-e968. DOI: 10.1016/j. wneu.2018.03.121. 
20.Burtsev A.V., Ryabykh S.O., Kotelnikov A.O., Gubin A.V. Klinicheskie aspekty sagittalnogo balansa u vzroslykh [Clinical aspects of the sagittal balance in the adults]. Genij Ortopedii, 2017, vol. 23, no. 2, pp. 228-235. (in Russian) DOI: 10.18019/1028-4427-2017-232-228-235.

21.Vialle R., Levassor N., Rillardon L., Templier A., Skalli W., Guigui P. Radiographic analysis of the sagittal alignment and balance of the spine in asymptomatic subjects. J. Bone Joint Surg. Am., 2005, vol. 87, no. 2, pp. 260-267. DOI:10.2106/JBJS.D.02043.

22.Liu S., Schwab F., Smith J.S., Klineberg E., Ames C.P., Mundis G., Hostin R., Kebaish K., Deviren V., Gupta M., Boachie-Adjei O., Hart R.A., Bess S., Lafage V. Likelihood of reaching minimal clinically important difference in adult spinal deformity: a comparison of operative and nonoperative treatment. Ochsner. J., 2014, vol. 14, no. 1, pp. 67-77.

23.Kim S.B., Lee G.S., Won Y.G., Jun J.B., Hwang C.M., Hong C.H. Radiologic findings of pelvic parameters related to sagittal balance. J. Korean Soc. Spine Surg., 2016, vol. 23, no. 3, pp. 197-205. DOI: 10.4184/ikss.2016.23.3.197.

24.Jackson R.P., McManus A.C. Radiographic analysis of sagittal plane alignment and balance in standing volunteers and patients with low back pain matched for age, sex, and size: A prospective controlled clinical study. Spine, 1994, vol. 19, no. 14, pp. $1611-1618$. DOI: 10.1097/00007632-199407001-00010.

25.Lafage V., Schwab F., Vira S., Patel A., Ungar B., Farcy J.P. Spino-pelvic parameters after surgery can be predicted: a preliminary formula and validation of standing alignment. Spine, 2011, vol. 36, no. 13, pp. 1037-1045. DOI: 10.1097/BRS.0b013e3181eb9469.

26.Van Royen B.J., De Gast A., Smit T.H. Deformity planning for sagittal plane corrective osteotomies of the spine in ankylosing spondylitis. Eur. Spine J., 2000, vol. 9, no. 6, pp. 492-498. DOI: 10.1007/s005860000183.

27.Schwab F., Patel A., Ungar B., Farcy J.P., Lafage V. Adult spinal deformity-postoperative standing imbalance: how much can you tolerate? An overview of key parameters in assessing alignment and planning corrective surgery. Spine, 2010, vol. 35, no. 25, pp. 2224-3221. DOI: 10.1097/BRS.0b013e3181ee6bd4.

28.Endo K., Suzuki H., Nishimura H., Tanaka H., Shishido T., Yamamoto K. Sagittal lumbar and pelvic alignment in the standing and sitting positions. J. Orthop. Sci., 2012, vol. 17, no. 6, pp. 682-686. DOI: 10.1007/s00776-012-0281-1.

29.Pereira M.A., FitzerGerald S.J., Gregg E.W., Joswiak M.L., Ryan W.J., Suminski R.R., Utter A.C., Zmuda J.M. A collection of physical activity questionnaires for health-related research. Med. Sci. Sports Exerc., 1997, vol. 29, no. 6 Suppl., pp. S1-S205.

30.Pate R.R., Pratt M., Blair S.N., Haskell W.L., Macera C.A., Bouchard C., Buchner D., Ettinger W., Heath G.W., King A.C. et al. Physical activity and public health. A recommendation from the Centers for Disease Control and Prevention and the American College of Sports. JAMA, 1995, vol. 273, no. 5, pp. 402-407. DOI: 10.1001/jama.273.5.402.

31.Craig C.L., Marshall A.L., Sjöström M., Bauman A.E., Booth M.L., Ainsworth B.E., Pratt M., Ekelund U., Yngve A., Sallis J.F., Oja P. International physical activity questionnaire: 12-country reliability and validity. Med. Sci. Sports Exerc., 2003, vol. 35, no. 8, pp. 1381-1395. DOI: 10.1249/01.MSS.0000078924.61453.FB.

32.Vaughn J.J., Schwend R.M. Sitting sagittal balance is different from standing balance in children with scoliosis. J. Pediatr. Orthop., 2014, vol. 34, no. 2, pp. 202-207. DOI: 10.1097/BPO.0000000000000075.

33.Philippot R., Wegrzyn J., Farizon F., Fessy M.H. Pelvic balance in sagittal and Lewinnek reference planes in the standing, supine and sitting positions. Orthop. Traumatol. Surg. Res., 2009, vol. 95, no. 1, pp. 70-76. DOI: 10.1016/j.otsr.2008.01.001.

34.Lee E.S., Ko C.W., Suh S.W., Kumar S., Kang I.K., Yang J.H. The effect of age on sagittal plane profile of the lumbar spine according to standing, supine, and various sitting positions. J. Orthop. Surg. Res., 2014, vol. 9, no. 1, pp. 1-10. DOI: 10.1186/1749-799X-9-11.

35.Shon W.Y., Sharma V., Keon O.J., Moon J.G., Suh D.H. Can pelvic tilting be ignored in total hip arthroplasty? Int. J. Surg. Case Rep., 2014, vol. 5, no. 9, pp. 633-636. DOI: 10.1016/j.ijscr.2014.07.015.

36.Hallager D.W., Hansen L.V., Dragsted C.R., Peytz N., Gehrchen M., Dahl B. A comprehensive analysis of the SRS-Schwab Adult Spinal Deformity Classification and Confounding Variables: A Prospective, Non-US Cross-sectional Study in 292 patients. Spine, 2016, vol. 41, no. 10, pp. E589-E597. DOI: 10.1097/BRS.0000000000001355.

37.Aoki Y., Nakajima A., Takahashi H., Sonobe M., Terajima F., Saito M., Takahashi K., Ohtori S., Watanabe A., Nakajima T., Takazawa M., Orita S., Eguchi Y., Nakagawa K. Influence of pelvic incidence-lumbar lordosis mismatch on surgical outcomes of short- segment transforaminal lumbar interbody fusion. BMC. Musculoskelet. Disord., 2015, vol. 16, pp. 213. DOI: 10.1186/ s12891-015-0676-1.

38.Averkiev V.A., Kudiashev A.L., Artiukh V.A., Nadulich K.A., Teremshonok A.V., Nagornyi E.B. Osobennosti sagittalnykh pozvonochno-tazovykh vzaimootnoshenii u patsientov s koksovertebralnym sindromom [Features of sagittal spinopelvic relations in patients with the coxo-vertebral syndrome]. Khirurgiia Pozvonochnika, 2012, no. 4, pp. 49-54. (in Russian)

39.Hey H.W.D., An Teo A.Q., Tan K.-A., Ng L.W.N., Lau L.-L., Liu K.-P.G., Wong H.-K. How the spine differs in standing and in sitting - important considerations for correction of spinal deformity. Spine J., 2017, vol. 17, no. 6, pp. 799-806. doi: 10.1016/j. spinee.2016.03.056.

40.Offierski C.M., MacNab I. Hip-spine syndrome. Spine, 1983, vol. 8, no. 3, pp. 316-321. DOI: 10.1097/00007632-19830400000014.

Received: 23.12.2019

\section{Information about the authors:}

1. Alexander O. Kotelnikov, M.D.,

Ilizarov National Medical Research Centre for Traumatology and Orthopedics, Kurgan, Russian Federation,

Email: carpediem1992@mail.ru

2. Sergey O. Ryabykh, M.D., Ph.D.,

Ilizarov National Medical Research Centre for Traumatology and Orthopedics, Kurgan, Russian Federation, Email: rso@mail.ru

3. Alexander V. Burtsev, M.D., Ph.D.,

Ilizarov National Medical Research Centre for Traumatology and Orthopedics, Kurgan, Russian Federation,

Email: bav31rus@mail.ru 